\title{
Manipulative bulletin board for early categorization
}

\author{
Chrysanthi Skoumpourdi
}

Abstract. According to various researchers categorization is a developmentally appropriate mathematical concept for young children. Classifying objects also relates to every day activities of human life. The manipulative bulletin board (MBB) served as a kind of auxiliary means for approaching categorization by young children. In this article we investigated the kind of MBB that pre-service early childhood education teachers constructed in order to involve children in tasks of categorization, as well as, the way children manipulated these boards in order to categorize items. The MBB, as teaching aids, facilitated the engagement of the children in different categorization processes.

Key words and phrases: manipulative bulletin board, categorization, early childhood.

ZDM Subject Classification: U31, U61.

\section{Introduction}

Children in early childhood can be engaged in significant mathematical thinking and reasoning. According to various researchers, among them Clements, (2004) and Seo \& Ginsburg, (2004) categorization is a mathematical concept developmentally appropriate for young children. Children can be involved in active learning with the aid of auxiliary means driven by diverse and challenging categorization tasks (Seo \& Ginsburg, 2004) based on authentic (Aubrey, 2006) and meaningful context familiar and comfortable to them (Clements, 2004). Such activities help children understand mathematical concepts, increase their motivation, enable them to think about particular concepts and procedures, make 
connections with other mathematical ideas and their applications in a real world contexts (Skoumpourdi, Kafoussi \& Tatsis, 2009).

The manipulative bulletin board (MBB) is an auxiliary teaching aid that could be valuable for teaching categorization to young children. This board can be developed with simple materials in real contexts and stimulate children's interests. This kind of auxiliary means could lead children into interesting mathematical avenues and help them learn mathematical concepts by allowing them the time to explore and experiment (Copple, 2004).

In this article we investigated the kind of MBB that pre-service early childhood teachers constructed in order to involve children in categorization tasks as well as the way children manipulated these boards in order to categorize items. Our research questions were the following:

1. What kind of MBB can be constructed for engaging children to categorization tasks?

2. Do the different MBB engage children in different categorization processes?

\section{Theoretical framework}

Categorization is the systematic arrangement in 'classes' according to established criteria. This includes sorting, grouping, classification, dividing, ordering and arranging objects. In every day human life there is seldom a collection that groups totally unrelated objects or phenomena (Fischbein \& Baltsan, 1999). This constraint expresses a principle of human normal conceptual way of thinking.

Concepts often serve as a means by which people may categorize different things. Children construct conceptual items very early on in life. When the conceptual item can be used in generating a visualized image of a past experience then an object concept has been constructed. When an object concept is constructed as permanent a collection of conceptual items is formed. Concepts serve as a means by which different things can be categorized on the basis of some common features (Steffe, 2004).

Cognitive scientists believe that adult humans, in order to hold information about various object classes, posse mental files or categorical representations. According to Quinn (2002), there are three main advantages of having a mindbrain system that categorizes experience. The first one is that categorization is important because it reduces the diversity of the physical world. The second is that it provides for organized storage and efficient retrieval of information in 
"tmcs-skoumpourdi" — 2011/5/13 - 20:44 — page $3-\# 3$

memory. And the third is the ability to respond equivalently to an indefinitely large number of examples from multiple categories.

Within cognitive psychology there are two major theories that attempt to describe the process of categorization, the classical view and the prototypical view. In the classical view, categories are represented by a set of defining features which are shared by all examples (Smith, Medin \& Medin, 1981). According to the prototypical view, there are ideal examples, the prototypes, which are serving as a basis for comparison when categorizing additional examples and non examples (Tsamir, Tirosh \& Levenson, 2008).

There are two contrasting views on how early categorization is developed. According to Rosch, Gottfried, Melloy-Carminar \& Bridger (1982, in Quinn, 2002) knowledge of categories is organized hierarchically into three levels: the superordinate level, the basic level and the subordinate level. Development, for Rosch et al., consists of grouping together basic-level representations to form the superordinate level and differentiating basic-level representations to form the subordinate level. The basic level, in which we do most of our thinking, is for Rosch, et al., (in Quinn, 2002) the most functional because the categories tend to posses significant numbers of attitudes in common, have similar shapes and invoke similar motor movements. Young infants form global and basic-level category representations in looking procedures (Behl-Chadha, 1996; Quinn, Eimas \& Rosenkrantz, 1993) whereas older infants form predominantly global category representations in object-exploration procedures (Mandler \& McDonough, 1993 \& 1998). Werner's tradition of differentiation theory is in contrast to Rosch's. Werner (1957, in Quinn, 2002) has suggested that the early development of categorization may proceed from more general to more specific representations.

\section{Early categorization}

In early childhood mathematics education the developmental continuum includes growth in the ability to classify (Clements, 2004). Classification activities help children to practice their observation skills and develop a strong understanding of the words "same" and "different". "Classification also gives children opportunities to reason, solve problems, make decisions, and be in control of their learning" (Gallenstein, 2004: 103).

Kindergarten offers many opportunities to children for classification. During free activities students use objects collected, such as buttons, seashells or ceramic tile pieces to sort, group, categorize and order. Children learn to sort objects by 
focusing and describing their properties as well as classifying according to these properties. For example, they might sort a collection of buttons into those which are red and those which are blue, constructing two groups, or into those with one, two, three or four holes, constructing four groups. They are also provided with lots of opportunities to explore different characteristics of materials and make classifications. While useful knowledge is being gained children are able to gain abstract mathematical understanding as they explore and manipulate concrete objects while classifying them. For example, by sorting seashells they discover the special characteristics or properties of objects and patterns found in shells in nature.

Classifying objects constitutes an every day activity. Children have to categorize objects from the arrangement of domestic goods (foods, clothing, games etc) in suitable places in the house, to the sorting of rubbish (glass, plastic, paper etc) for their deposition in the appropriate recycling bins.

Seo \& Ginsburg (2004) in order to determine what is developmentally appropriate for early mathematics education observed young children's activities and attempted to learn more about their spontaneous mathematical interests and questions. The results showed that young children engaged in a considerable amount of mathematical activity during their free play, such as, classification, among others. Classification in those activities involved sorting, grouping or categorizing.

\section{Method}

Fifty four pre-service early childhood education teachers in third semester were asked to design and construct a manipulative bulletin board (MBB) that could engage children in tasks of categorization. No other suggestions were given. 25 children (5-6 years of age) from a kindergarten of a municipal primary school were invited to interact with these manipulative bulletin boards. Children in teams (3-4 children), that created themselves, were involved in the manipulation of bulletin boards and the process was videotaped.

Pre-service early childhood education teachers asked the children to classify the items ( $1^{\text {st }}$ task: "Can you classify the items?") letting them manipulate the bulletin boards. After the children's initial classification, pre-service teachers invited them to classify objects/pictures in different manners in order to explore other ways of classification $\left(2^{\text {nd }}, 3^{\text {rd }} \ldots\right.$ task: "Can you classify the items in another way?"). 
Our analysis was focused on two main factors: the kind of manipulative bulletin boards that were constructed for engaging children to categorization activities and the way children manipulated those bulletin boards.

\section{Results}

The manipulative bulletin boards (MBB) constructed

In all the manipulative bulletin boards which were developed by pre-service early childhood education teachers, drawings, images and concrete objects were used instead of text because of the young age of the children.

Although all the MBB were designed to reflect the concept of categorization, the way they were constructed, as well as the context, differed. There were two main types of construction. The first type included the two-dimensional MBB (fig. 1(a)), that is to say a simple drawing on the main board with the additional materials given in an envelope. Children in this case had to stick pictures (additional materials) on the MBB. The second type was a three-dimensional MBB. In this type the MBB represented situations similar to reality (fig. 1(b)). The children had to put or arrange miniatures of real objects (additional materials) on the board.

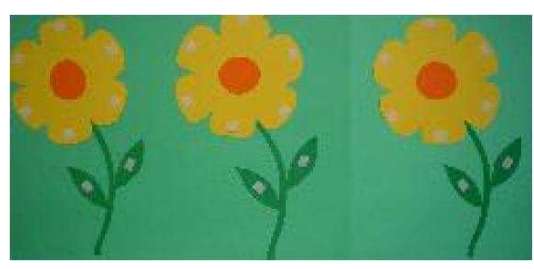

(a) Two-dimensional MBB

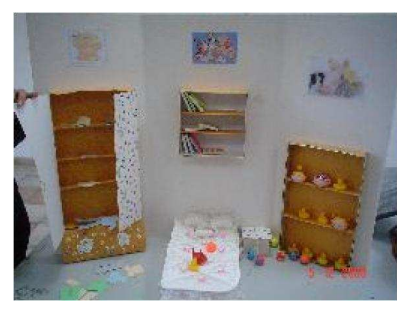

(b) Three-dimensional MBB

Figure 1

The contexts of the MBB, included the following topics: 'flowers', 'fishing', 'animals', 'magic wardrobe', 'bedroom' and 'faces'.

In the 'flowers', 'fishing', 'animals' and 'magic wardrobe' MBB, the boards were simple and contained either an only title, like 'ANIMALS' or separate objects (like vases, fishing rods, living places and shelves respectively) which represented different 'areas' in each board. The purpose was the sorting of the several flowers, 
fish, animals and other items such as clothes, accessories, shoes, foods etc., that were given to the children, as additional materials, according to the different 'areas'.

The 'faces' board consisted of large pieces of blank cards on which the children were prompted to use the additional materials in such a way as to construct a woman's and a man' face. The 'bedroom' board, represented reality in miniature. The main purpose for the children was to put the additional materials (like toys, blanket and clothes) in the suitable places on the board.

The additional materials that were constructed for each MBB were either structured or unstructured. More specifically, for the 'flowers' and the 'fishing' manipulative bulletin boards, the materials were structured, whereas for the 'animals', the 'magic wardrobe', the 'bedroom' and the 'faces' boards, the materials were unstructured. Structured materials were constructed in a specific manner, according to specific properties. For example, for the 'fishing' manipulative bulletin board (fig. 2(a)), fish were of three sizes and three colours. However, for the 'magic wardrobe' manipulative bulletin board, the additional materials given were iconic representations of real life objects (fig. 2(b)). These materials were clothes: a pair of trousers, a top, a hat, a pair of shorts; foodstuff: a strawberry, an ice-cream, a candy, a banana, an apple, a cake, a cherry; animals: a dog, a rabbit, a giraffe and a cat; and means of transportation: a car, a plane, a train and a boat. The additional materials for the 'faces' board consisted of hats, a moustache, hair, eyes, noses, lips, glasses, eye brows, tie, and a bow tie.

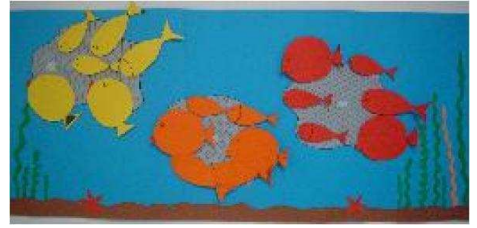

(a) 'Fishing' MBB

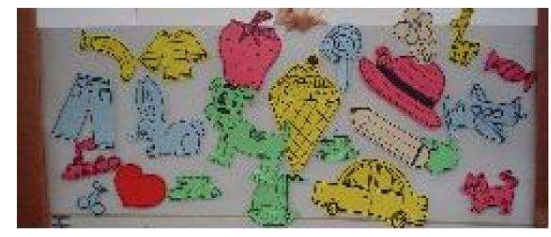

(b) Additional materials given for the 'magic wardrobe'

Figure 2

The MBB required object/picture manipulation in different ways. Each board introduced a different scenario. The scenario always related to children' everyday routine and was based on their experiences so that it would be familiar to them.

There were several categories that children could make. For example, for the 'animals' manipulative bulletin board, sorting could be made according to the 
number of legs, to the existence or non existence of a tail, to the place where animals live, etc. For the 'flowers' and the 'fishing' manipulative bulletin boards, the categorization could be according to the different kinds, colors, and sizes of flowers and fish. For the 'magic wardrobe' board, objects could be categorized in different selves according to specific characteristics (such as clothes, food, animals, transportation means).

Children's manipulation of the bulletin boards

With the use of the MBB children were actively involved in activities that had meaning for them and offered opportunities to use their informal knowledge and their strategies for the classification of objects. It appeared that they categorized items in different ways (Table 1).

Table 1. Children's actions on each Bulletin Board and their interpretation

\begin{tabular}{|c|c|c|}
\hline $\begin{array}{l}\text { Bulletin } \\
\text { Board }\end{array}$ & Children's actions & Interpretation \\
\hline "Flowers" & $\begin{array}{l}\text { Placed flowers on vases ran- } \\
\text { domly and according to color. }\end{array}$ & $\begin{array}{l}\text { Demonstrated ability to cate- } \\
\text { gorize items in multiple ways. }\end{array}$ \\
\hline "Fishing" & $\begin{array}{l}\text { Placed fish on fishing rod ac- } \\
\text { cording to size, color and } \\
\text { shape. }\end{array}$ & $\begin{array}{l}\text { Demonstrated ability to cate- } \\
\text { gorize items in multiple ways. }\end{array}$ \\
\hline "Animals" & $\begin{array}{l}\text { Placed animals on different } \\
\text { places according to: number } \\
\text { of legs, were they accustomed } \\
\text { to see them as well as whether } \\
\text { they had a tail, they laid eggs, } \\
\text { they had horns. }\end{array}$ & $\begin{array}{l}\text { Demonstrated ability to cate- } \\
\text { gorize items in multiple ways. }\end{array}$ \\
\hline $\begin{array}{l}\text { "Magic } \\
\text { wardrobe" }\end{array}$ & $\begin{array}{l}\text { Placed objects on selves ac- } \\
\text { cording to their type. }\end{array}$ & $\begin{array}{l}\text { Demonstrated ability to cate- } \\
\text { gorize items in one way. }\end{array}$ \\
\hline "Bedroom" & $\begin{array}{l}\text { Placed items on places ac- } \\
\text { cording to their usage. }\end{array}$ & $\begin{array}{l}\text { Demonstrated ability to cate- } \\
\text { gorize items in multiple ways. }\end{array}$ \\
\hline "Faces" & Rotating - Experimenting. & $\begin{array}{l}\text { Demonstrated ability to cate- } \\
\text { gorize items in one way. }\end{array}$ \\
\hline
\end{tabular}

For the 'flowers' board, the children tried to make two bunches of flowers one for each vase. The first flower placement was random (fig. 3(a)). When they 
remade the bouquets they placed all the brown flowers in the first vase and the rest in the second (fig. 3(b)). Then they put all the purple flowers in the first vase and all the red in the other leaving the rest on the table (fig. 3(c)).

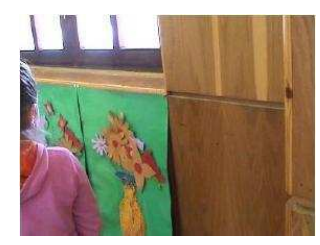

(a) $1^{\text {st }}$ categ.

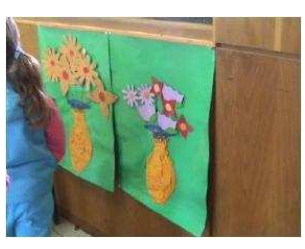

(b) $2^{\text {nd }}$ categ.

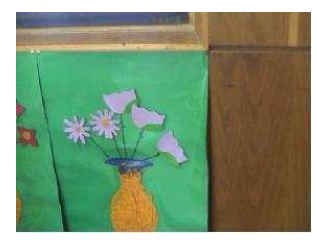

(c) $3^{\text {rd }}$ categ.

Figure 3

In the 'fishing' board, the children initially stuck randomly the different fish on the three fishing rods. On the first fishing rod they put one big orange fish, two intermediate orange fish, one small orange fish and one small yellow fish; on the second fishing rod they put two big yellow, one big orange and one intermediate red fish. Finally, on the 3rd they put two big red, four intermediate red and one small yellow fish (fig. 4(a)). On further attempts, they separated the fish according to their -therefore they placed the yellow fish on the first fishing rod, the red on the second and on the third the orange fish (fig. 4(b)). Finally, they separated the fish according to their shape. Therefore they placed the big fish on the first fishing rod and they named them 'the fat fish', on the second the intermediate fish were placed and they were named 'the middle-sized fish' and on the third the small fish which they named 'the small fish'. Sometimes the children could not easily differentiate the small from the intermediate fish so they placed the one above the other in order to observe whether they had the same size or not when deciding where to place them.

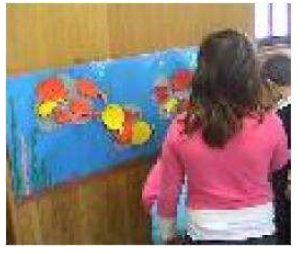

(a) $1^{\text {st }}$ categorization

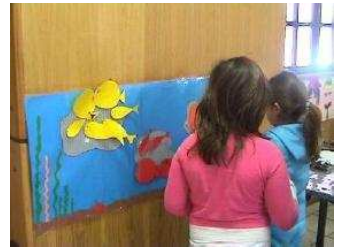

(b) $2^{\text {nd }}$ categorization

Figure 4
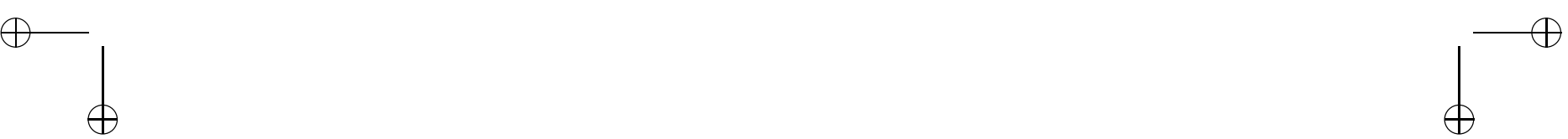
Regarding the 'animals' board, the children separated the animals they were more accustomed to see in the air, in the sea and on the ground. When prompted to classify in another way they categorised them according to whether animals had a tail or not, whether they laid eggs, whether they had four, two or no legs, and whether they had horns.

In the 'magic wardrobe' board the children categorized the objects according to their type creating four categories which they named 'clothes', 'fruits', 'animals', and 'means of transportation' which takes us on excursions.

Concerning the 'bedroom' board the children put each one in a specific place in the room. Initially they placed decorative objects on the furniture. Then they arranged the clothes in the wardrobe setting aside other objects on the bedside table. Finally, they made the bed with the sheet and the quilt. When they were asked if they could arrange the given objects in a different way they tried out the sheet as a curtain and the quilt as a carpet.

The 'faces' was the most difficult manipulative bulletin board for the children. Apart from familiar pieces like eyes, noses and lips which were easy to place on the faces there were other pieces which confused the children because they could not understand what was being represented. Although they tried to put them on the face they could not find a specific place to fit them (fig. 5(a)). Thus they spent some time rotating each piece in all directions, experimenting with different places until they decided on a location (fig. 5(b)).

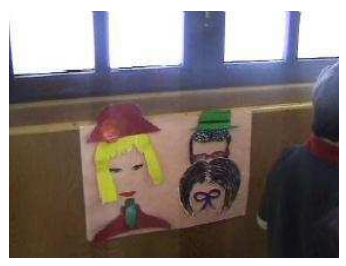

(a) Children's first construction on 'faces'

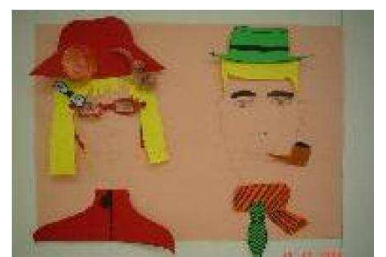

(b) Children's final construction on 'faces'

Figure 5

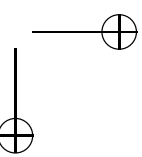




$$
\text { "tmcs-skoumpourdi" — 2011/5/13 — 20:44 — page } 10 \text { — \#10 }
$$

\section{Discussion - conclusions}

Various manipulative bulletin boards (MBB) were constructed by pre-service early childhood education teachers in order to involve young students in categorization activities. Through the different boards which were two or three dimensional, related to several topics and the use of variety of materials, children were engaged in different categorization processes.

The process of the categorization was associated with the kind of the MBB. Children formed predominantly global category representations in object-exploration procedures but also the development of their categorization proceeded from more general to more specific representations. When the material to be classified was structured the categories were initially made randomly forming the superordinate level. In the regrouping process they put things together according to a specific property (colour, type, kind, etc.,) forming the basic and the subordinate level respectively. With the unstructured materials children dedicated some time to observing and identifying characteristics of the objects. In the cases where unstructured materials were miniatures of real objects children categorized them, according to their 'right' place in real life. Probably, that happened because the context was similar to their everyday routine. But in the case where the unstructured material was for a construction on the MBB, children had some difficulty. Sometimes they tried to put pieces in places where they did not fit. This may have happened because on one hand this type of material formed the subordinate level and on the other they did not know and could not imagine how the MBB would look like when completed.

According to Ziemba and Hoffman (2006) "when young children are using manipulatives ...their teachers are better able to assess their varying levels of development" (p. 240). Through this practical experience pre-service teachers developed their own teaching aid, to pose meaningful mathematical tasks that require students to reason, communicate, represent, and make mathematical connections. The construction and use of MBB in the teaching/learning process of mathematics, offered teachers the opportunity to create various situations that encouraged the active engagement of students in mathematical tasks. It also added to the teachers' learning by giving them information about children's informal knowledge and their adopted strategies for the categorization process when realized activities in small groups. Then moving from small group work to tasks performed individually would enable teachers to assess the developmental level of individual pupils in categorization tasks. 
It seemed that the MBB could be an auxiliary means which could involve children in significant mathematical thinking that provoked their curiosity in an authentic way, with repeated experiences. As children categorized objects they formed their own categories by observing and identifying similarities and differences of objects and pictures in the different situations. Through manipulation of the MBB children were driven in self-directed engagement with mathematics. Children discovered different types of concepts of classification at their own developmental level which challenges them to think inductively as they classified objects.

For justifying MBB's use, and as an extension of this research, a study which would compare the results of the children doing the same tasks of categorization by verbal instruction only and comparing the same activities with the use of MBB, can be conducted.

\section{References}

[1] R. Aubrey, Editorial: the components of authentic learning, Journal of Authentic Learning 3, no. 1, 2006, 1-10.

[2] G. Behl-Chadha, Basic level and superordinate-like categorical representations in early infancy, Cognition 60, 1996, 105-141.

[3] D. Clements, Major themes and recommendations, Engaging young children in mathematics: standards for early childhood mathematics education, (D. Clements and J. Sarama, eds.), Lawrence Erlbaum Associates Publishers, USA, 2004, 7-72.

[4] C. Copple, Mathematics curriculum in the early childhood context, Engaging young children in mathematics: standards for early childhood mathematics education, (D. Clements \& J. Sarama, eds.), Lawrence Erlbaum Associates Publishers, USA, 2004, 83-87.

[5] E. Fischbein and M. Baltsan, The mathematical concept of set and the 'collection' model, Educational Studies in Mathematics 37, 1999, 1-22.

[6] N. Gallenstein, Creative discovery through classification, Teaching Children Mathematics 11, no. 2, 2004, 103-108.

[7] J. Mandler and L. McDonough, Concept formation in infancy, Cognitive Development 8, no. 3, 1993, 291-318.

[8] J. Mandler and L. McDonough, On developing a knowledge base in infancy, Developmental Psychology 34, 1998, 1274-1278.

[9] P Quinn, P. Eimas and S. Rosenkrantz, Evidence for representations of perceptually similar natural categories by 3 -month-old and 4-month-old infants, Perception 22, no. $4,1993,463-475$. 
"tmcs-skoumpourdi" — 2011/5/13 — 20:44 — page 12 — \#12

[10] P. Quinn, Blackwell Handbook of childhood cognitive development, (U. Goswami, ed.), Blackwell Publishing, 2002, 84-101.

[11] K-H. Seo and H. Ginsburg, Engaging young children in mathematics: Standards for early childhood mathematics education, (D. Clements and J. Sarama, eds.), Lawrence Erlbaum Associates Publishers, 2004, 91-104.

[12] C. Skoumpourdi, S. Kafoussi and K. Tatsis, Designing probabilistic tasks for kindergartners, Journal of Early Childhood Research 7, no. 2, 2009, 153-172.

[13] E. Smith, D. Medin and D. Medin, Categories and concepts, Cambridge, MA: Harvard University, 1981.

[14] L. Steffe, Engaging young children in mathematics: standards for early childhood mathematics education, (D. Clements and J. Sarama, eds.), Lawrence Erlbaum Associates Publishers, USA, 2004, 221-251.

[15] P. Tsamir, D. Tirosh and E. Levenson, Intuitive nonexamples: the case of triangles, Educational Studies in Mathematics 69, no. 2, 2008, 81-95.

[16] E. Ziemba and J. Hoffman, Sorting and patterning in kindergarten: from activities to assessment, Teaching Children Mathematics 12, no. 5, 2006, 236-241.

CHRYSANTHI SKOUMPOURDI

UNIVERSITY OF THE AEGEAN

KAMEIROS BUILDING

25TH MARTIOU STREET

85100 RHODES

GREECE

E-mail: kara@rhodes.aegean.gr

(Received May, 2010) 